\title{
PENGARUH PERILAKU BELAJAR TARUNA/I SEKOLAH TINGGI TRANSPORTASI DARAT TERHADAP INDEKS AKADEMIK
}

\author{
Ir. Nico D Djajasinga, M.Sc \\ Dosen STTD \\ J1. Raya Setu No. 89, Cibuntu, \\ Cibitung, Bekasi 17520 \\ Telp./Fax : (021) 8254640
}

\author{
Utut W. M.Sc \\ Dosen STTD \\ Cibitung, Bekasi 17520 \\ Telp./Fax : (021) 8254640
}

Jl. Raya Setu No. 89, Cibuntu,

\author{
Ir. J R C Hosang \\ Dosen STTD \\ Jl. Raya Setu No. 89, Cibuntu, \\ Cibitung, Bekasi 17520 \\ Telp./Fax : (021) 8254640
}

\author{
Eka Arista, M.Sc \\ Dosen STTD \\ J1. Raya Setu No. 89, Cibuntu, \\ Cibitung, Bekasi 17520 \\ Telp./Fax : (021) 8254640
}

\author{
Probo Yudha, S.SiT \\ Dosen STTD \\ J1. Raya Setu No. 89, Cibuntu, \\ Cibitung, Bekasi 17520 \\ Telp./Fax : (021) 8254640
}

\begin{abstract}
ABSTRAKSI
Fenomena kualitas belajar di Perguruan Tinggi seringkali dipertanyakan dalam hal mencetak tenaga yang profesional, apakah mampu menjawab kebutuhan dunia kerja. Para lulusan Perguruan Tinggi banyak mengalami perception gap, yaitu perbedaan pandangan dalam menyelesaikan masalah yang terjadi di dunia kerja. Prakasa (2003) dalam Dwi Hastuti (2003) mengkritisi pendidikan tinggi di bidang/ ilmu Akuntansi bahwa output mahasiswa kurang memiliki ketrampilan dan orientasi profesional yang diperlukan guna mengimplementasikan pengetahuan yang diserap di bangku kuliah ke dunia kerja. Kelemahan ini diperparah lagi dengan kondisi bahwa mahasiswa kurang mendapat pendidikan yang memadai dalam ketrampilan intelektual, komunikasi serta interpersonal.
\end{abstract}

Prestasi akademik yang dicapai seseorang mahasiswa merupakan hasil interaksi antara berbagai faktor yang mempengaruhinya, baik dalam diri mahasiswa, maupun luar diri mahasiswa. Pengenalan terhadap factor-faktor yang mempengaruhi prestasi akademik diperlukan untuk memahami bagaimana perubahan dalam deteminan tersebut berhubungan dengan perubahan prestasi, sehingga akhirnya menjadi rekomendasi bagi pengambilan kebijakan dalam pendidikan akuntansi (Syukri, 1995).

Dalam realita para dosen sering merasa harus melakukan berbagai perubahan dalam pola mengajar agar tidak membuat mahasiswa cepat bosan. Hal itu dilakukan dengan tujuan sebenarnya adalah agar materi yang diajarkan dapat diterima dengan baik oleh mahasiswa. Namun demikian seringkali pula para dosen menjadi putus asa karena dengan model mengajar apapun masih juga materi yang disampaikan dinilai kurang optimal diterima oleh mahasiswa. Kondisi demikian akhirnya menimbulkan pertanyaan yang dapat dijawab melalui penelitian ini, yaitu untuk mengkaji lebih dalam tentang pengaruh perilaku belajar dan motivasi terhadap prestasi akademik mahasiswa dengan fokus responden yaitu Taruna/i runtuk mengetahui kondisi/ pengaruh input mahasiswa baru dimana tempat peneliti bekerja di Sekolah Tinggi Transportasi Darat

Hasil penelitian memperlihatkan bahwa terdapat pengaruh kebiasan mengikuti pelajaran, kebiasaan membaca buku teks, kunjungan ke perpustakaan, kebiasaan menghadapi ujian dan kebiasaan mencari data dibiasakan terhadap indeks prestasi akademik tidak dapat dijadikan jaminan bahwa indeks prestasi akan tinggi pula. Untuk itu diharapkan pimpinan melengkapi koleksi buku perpustakaan tidak hanya dengan buku teks, juga data data sekunder seperti data 
BPS, publikasi ilmiah dan karya ilmiah lainnya dan para dosen agar senantiasa memberi latihan dan kuis sebagai latihan ujian

\begin{abstract}
The phenomenon of the quality of college, are often questionable in terms of printing professional staff, is able to answer the needs of the workforce. College graduates experienced many perception gap, namely the differences in solving problems that occur in the world of work. Prakasa (2003) in Dwi Hastuti (2003) criticized in the field of higher education / science output accounting that students lack the skills and professional orientation necessary to implement the knowledge absorbed in college to the work world. This weakness is compounded by the conditions that the students lack an adequate education in intellectual skills, and interpersonal communication.
\end{abstract}

One achieves academic achievement of students is the result of interaction between the various factors that influence it, both within the students, as well as external students. The introduction of the factors that affect academic achievement is needed to understand how changes in the deteminan associated with changes in achievement, so it ended up being a recommendation for policy decision making in accounting education (Shukri, 1995).

In reality the lecturers often feel compelled to make changes in the pattern of teaching that does not make student bored quickly. This was done with the real goal is to be the material that is taught well received by students. However, the lecturers often also be frustrating because with any teaching model is also the material presented rated less than optimal received by students. Such conditions ultimately raises questions that can be answered through this research, which is to examine more deeply about the influence learning behavior and motivation of the students' academic achievement with a focus on the respondents, Cadets, to know the condition / influence of input of new students in which a researcher working in the College of Transport Land

The results showed that there are significant lessons to follow the habit, the habit of reading textbooks, visits to the library, habits and customs exams familiarized search for data on the index of academic achievement can not be guaranteed that the performance index will be higher as well. To the leaders are expected to complete the collection of library books not only with textbooks, secondary data as well as data on BPS data, scientific publications and other scientific work and the teachers to always give exercises and quizzes as a practice test.

\title{
PENDAHULUAN
}

\section{A. Latar Belakang}

Fenomena kualitas belajar di Perguruan Tinggi seringkali dipertanyakan dalam hal mencetak tenaga yang profesional, apakah mampu menjawab kebutuhan dunia kerja. Para lulusan Perguruan Tinggi banyak mengalami perception gap, yaitu perbedaan pandangan dalam menyelesaikan masalah yang terjadi di dunia kerja. Prakasa (2003) dalam Dwi Hastuti (2003) mengkritisi pendidikan tinggi di bidang/ ilmu Akuntansi bahwa output mahasiswa kurang memiliki ketrampilan dan orientasi profesional yang 
diperlukan guna mengimplementasikan pengetahuan yang diserap di bangku kuliah ke dunia kerja. Kelemahan ini diperparah lagi dengan kondisi bahwa mahasiswa kurang mendapat pendidikan yang memadai dalam ketrampilan intelektual, komunikasi serta interpersonal.

Prestasi akademik yang dicapai seseorang mahasiswa merupakan hasil interaksi antara berbagai faktor yang mempengaruhinya, baik dalam diri mahasiswa, maupun luar diri mahasiswa. Pengenalan terhadap factor-faktor yang mempengaruhi prestasi akademik diperlukan untuk memahami bagaimana perubahan dalam deteminan tersebut berhubungan dengan perubahan prestasi, sehingga akhirnya menjadi rekomendasi bagi pengambilan kebijakan dalam pendidikan akuntansi (Syukri, 1995).

Dalam realita para dosen sering merasa harus melakukan berbagai perubahan dalam pola mengajar agar tidak membuat mahasiswa cepat bosan. Hal itu dilakukan dengan tujuan sebenarnya adalah agar materi yang diajarkan dapat diterima dengan baik oleh mahasiswa. Namun demikian seringkali pula para dosen menjadi putus asa karena dengan model mengajar apapun masih juga materi yang disampaikan dinilai kurang optimal diterima oleh mahasiswa. Kondisi demikian akhirnya menimbulkan pertanyaan yang dapat dijawab melalui penelitian ini, yaitu untuk mengkaji lebih dalam tentang pengaruh perilaku belajar dan motivasi terhadap prestasi akademik mahasiswa dengan fokus responden yaitu Taruna/i runtuk mengetahui kondisi/ pengaruh input mahasiswa baru dimana tempat peneliti bekerja di Sekolah Tinggi Transportasi Darat.

\section{B. Rumusan Masalah}

Penelitian ini memiliki rumusan masalah sebagai berikut :

1. Apakah kebiasaan mengikuti pelajaran berpengaruh terhadap indeks prestasi terhadap?

2. Apakah kebiasaan membaca buku teks berpengaruh terhadap indeks prestasi terhadap kebiasaan membaca buku teks

3. Apakah kunjungan ke perpustakaan berpengaruh terhadap indeks prestasi ?

4. Apakah kebiasaan menghadapi ujian berpengaruh terhadap indeks prestasi ?

5. Apakah kebiasaan mencari data berpengaruh terhadap indeks prestasi terhadap?

\section{Tujuan Penelitian}

Penelitian ini bertujuan :

1. Terdapat pengaruh kebiasaan mengikuti pelajaran, kebiasaan membaca buku teks, kebiasaan kunjungan ke perpustakaan terhadap indeks prestasi, kebiasaan menghadapi ujian, kebiasaan mencari data terhadap indeks prestasi 
2. Memperoleh gambaran hasil kebiasaan perilaku belajar Taruna terhadap Indeks Prestasi

\section{Pembatasan Penelitian}

Adapun batasan masalah dalam penelitian ini adalah :

1. Penelitian hanya dibatasi pada faktor kebiasaan mengikuti pelajaran, kebiasaan membaca buku teks, kunjungan ke perpustakaan, kebiasaan menghadapi ujian, kebiasaan mencari data.

2. Penelitian dilakukan pada taruna/i angkatan $2013 / 2014$ - 2015/2016 Sekolah Tinggi Transportasi Darat Bekasi, semester genap 2015/2016.

\section{TINJAUAN PUSTAKA}

\section{A. Belajar}

Belajar adalah suatu proses usaha yang kompleks dilakukan seseorang dari tidak tahu menjadi tahu, dan tidak mengerti menjadi mengerti dan sebagainya, untuk memperoleh perubahan tingkah laku yang lebih baik secara keseluruhan akibat interaksinya dengan lingkugan.

\section{B. Kualitas Belajar}

Proses belajar diperlukan perilaku belajar yang sesuai dengan tujun pendidikan, dimana dengan perilaku belajar tersebut tujuan pendidikan dapat dicapai secara efektif dan efisien, sehingga prestasi akademik dapat ditingkatkan. Perilaku belajar, sering juga disebut kebiasaan belajar, merupakan dimensi belajar yang dilakukan individu secara berulang-ulang sehingga menjadi otomatis atau spontan. Perilaku ini akan mempengaruhi prestasi belajar (Rampengan, 1997)

Proses belajar akan selalu berawal dan adanya motivasi dan tujuan, baik dinyatakan secara eksplisit ataupun implisit, yang diaksudkan untuk memberi arah bagi pencapaian yang ingin diperoleh pada rentang waktu tertentu. Dalam konteks pendidikan tradisional, seperti yang masih dianut dalam kurikulum pendidikan di Indonesia, salah satu ukuran yang dipakai untuk menilai keberhasilan proses belajar tersebut adalah prestasi akademik peserta didik. Prestasi atau kinerja (performance) merupakan hasil akhir dari suatu kegiatan, sedangkan prestasi belajar merupakan hasil akhir dari proses belajar. Untuk mengetahui prestasi belajar yang diperoleh mahasiswa setelah proses belajar mengajar berlangsung maka diadakan evaluasi.

\section{Kerangka Berfikir}

Belajar adalah kata kunci dalam setiap usaha sehingga tanpa belajar sesungguhnya tidak 
ada pendidikan. Menurut Chaplin (2009:65) "belajar adalah perolehan perubahan tingkah laku yang relatif menetap sebagai akibat latihan dan pengalaman".

Gambar.1 Kerangka pemikiran

\begin{tabular}{|l|l|}
\hline \multicolumn{1}{|c|}{ Variabel Independen } \\
\multicolumn{1}{|c|}{ Perilaku Belajar (X): } \\
Kebiasaan mengikuti pelajaran (X1) \\
Kebiasaan membaca buku teks (X2) \\
Kebiasaan ke perpustakaan (X3) \\
Kebiasaan menghadapi ujian (X4) \\
Kebiasaan mencari data (X5)
\end{tabular}

\section{METODOLOGI PENELITIAN}

\section{A. Lokasi Penelitian}

Penilaian tentang pengaruh perilaku belajar terhadap prestasi akademik taruna/i ini dilakukan di Sekolah Tinggi Tansportasi Darat pada taruna/i yang mengikuti kuliah pada semester genap 2015/2016. Penelitian ini menggunakan desain deksriptif kausal. Penelitian deskriptif dimaksud untuk mendapatkan gambaran secara sistematis, akurat mengenai fakta-fakta yang menyangkut kebiasaan belajar dan prestasi yang diperoleh taruna/i angkatan 2013/2014 s/d 2015/2016 semasa mengikuti perkuliahan semester genap 2016.

\section{B. Metode Penelitian}

Metode penelitian yang digunakan adalah metode deskriptip kualitatif dan kuantitatif yang dianalisis secara kuantitatif dengan pengembangan metode Regresi Linear berganda. Sampel yang digunakan sesuai dengan rumus slovin diperoleh sampel 100 responden. Adapun penarikan sampel dilakukan dengan metode non probability sampling, yakni Taruna/I STTD yang memenuhi kriteria populasi dan memiliki peluang yang sama untuk dipilih sebagai sampel.

Data yang digunakan berupa data sekunder dan data primer. Data sekunder berupa jumlah Taruna/i, fasilitas pendidikan. Sedangkan untuk data primer yaitu berupa penilaian responden diperoleh survei dengan membagikan kuisioner kepada Taruna/i STTD.

\section{Tahapan Penelitian}

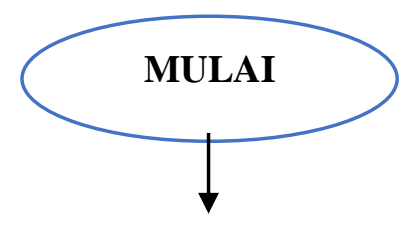




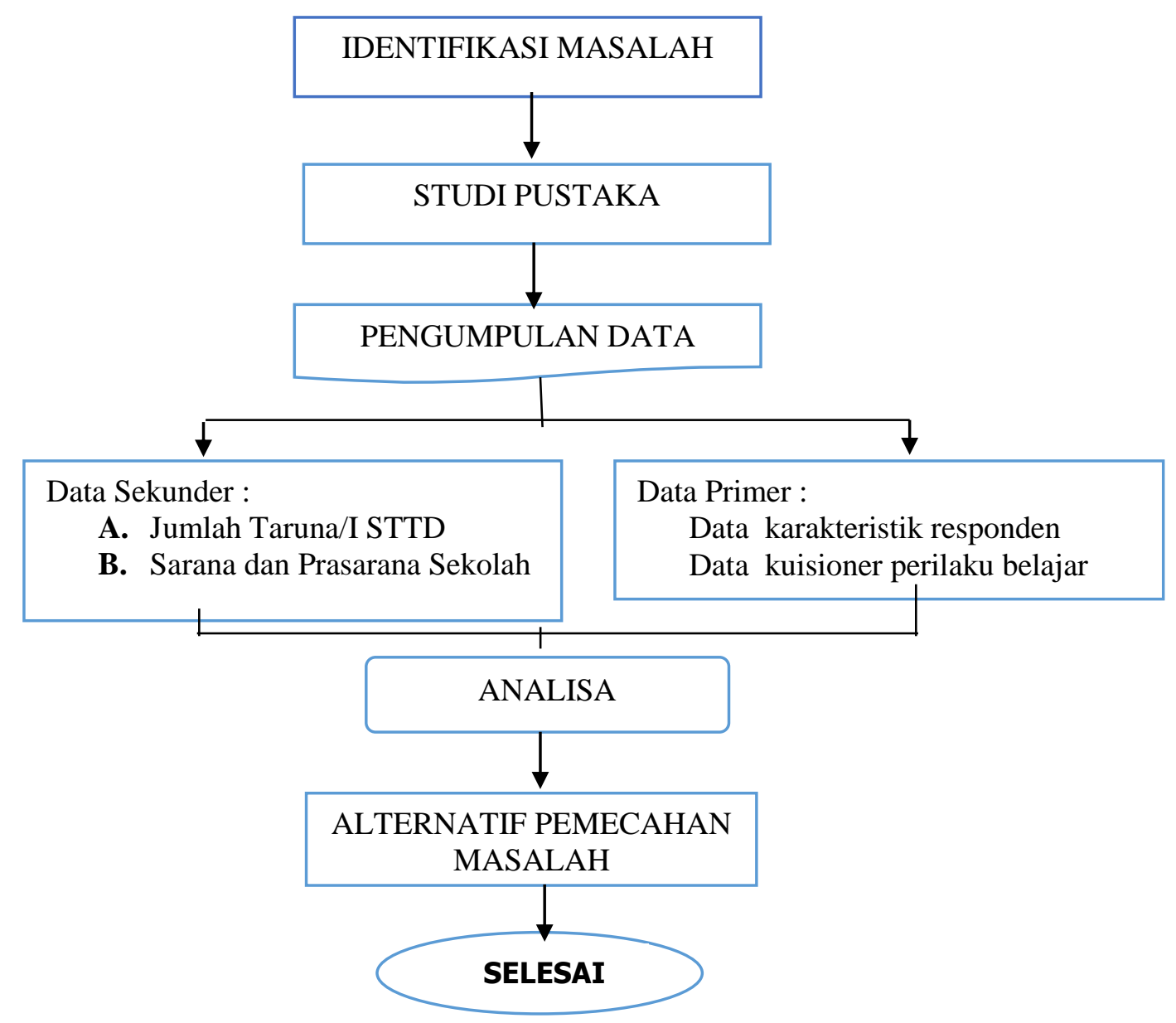

Gambar. 2 Alur Penelitian

\section{Metode Analisis}

Untuk menganalisis data sampel melalui tahapan sebagai berikut :

1. Pengolahan data

2. Uji Reabilitas

3. Uji Normalitas

4. Uji Autokorelasi

5. Uji Hipotesis

\section{HASIL PENELITIAN DAN PEMBAHASAN}

\section{A. Karakteristik Responden}

\section{Jenis Kelamin}

Taruna/i yang diteliti sebanyak 100 orang terdiri dari 65 Taruna (65\%) dan 35 Taruni (35\%). Dengan demikian dapat dilihat bahwa Taruni lebih banyak dari pada Taruna. 
Tabel 4.1 Jenis Kelamin

\begin{tabular}{|ll|l|l|l|l|}
\hline & Frequency & Percent & Valid Percent & Cumulative Percent \\
\hline Valid & L & 65 & 65,0 & 65,0 & 65,0 \\
& $\mathrm{P}$ & 35 & 35,0 & 35,0 & 100,0 \\
& Total & 100 & 100,0 & 100,0 & \\
\hline
\end{tabular}

\section{Jumlah SKS}

Berdasarkan jumlah SKS dapat dilihat bahwa jumlah SKS 20 sebanyak 12 Taruna/i, jumlah SKS 22 sebanyak 49 Taruna/i dan jumlah SKS 23 sebanyak 39 Taruna/i. Perbedaan SKS terkait dengan program studi yang berbeda. Dengan demikian dapat diartikan bahwa penelitian ini mayoritas Taruna/i dengan jumlah SKS 22.

Tabel 4.2 Jumlah SKS

\begin{tabular}{|ll|l|l|l|l|}
\hline & Frequency & Percent & Valid Percent & Cumulative Percent \\
\hline Valid & 20 & 12 & 12,0 & 12,0 & 12,0 \\
& 22 & 49 & 49,0 & 49,0 & 61,0 \\
& 23 & 39 & 39,0 & 39,0 & 100,0 \\
& Total & 100 & 100,0 & 100,0 & \\
\hline
\end{tabular}

\section{Indeks Prestasi (IPK) semester lalu}

Berdasarkan IPK semester lalu dapat dilihat bahwa jumlah IPK $<2,5$ sebanyak 2 Taruna/i, jumlah IPK 2,6 - 3 sebanyak 42 TANAaruna/i, jumlah IPK 3,1 - 3,5 sebanyak 40 Taruna/i, dan jumlah IPK 3,6 - 4 sebanyak 15 Taruna/i. Dengan demikian penelitian ini didominasi oleh Taruna/i yang memiliki IPK 2,6 - 3 .

Tabel 4.3 IPK Semester lalu

\begin{tabular}{|ll|l|l|l|l|}
\hline & Frequency & Percent & Valid Percent & Cumulative Percent \\
\hline Valid & $<2,5$ & 2 & 2,0 & 2,0 & 2,0 \\
& $2,6-3$ & 43 & 43,0 & 43,0 & 45,0 \\
$3,1-3,5$ & 40 & 40,0 & 40,0 & 85,0 \\
$3,5-4$ & 15 & 15,0 & 15,0 & 100,0 \\
& Total & 100 & 100,0 & 100,0 & \\
\hline
\end{tabular}

\section{Pekerjaan Orang Tua}


Berdasarkan pekerjaan orang tua Taruna/i diketahui bahwa orang tua Taruna/i yang bekerja sebagai pegawai BUMN 3 orang, sebagai guru 8 orang, sebagai petani 3 orang, sebagai PNS 42, Polri 8 orang, Pegawai swasta 10 orang, wiraswasta 5 orang, dan wirausaha 21 orang.

Tabel 4. 4 Pekerjaan Orang Tua

\begin{tabular}{|ll|l|l|l|l|}
\hline & & Frequency & Percent & Valid Percent & Cumulative Percent \\
\hline Valid & BUMN & 3 & 3,0 & 3,0 & 3,0 \\
& GURU & 8 & 8,0 & 8,0 & 11,0 \\
& PETANI & 3 & 3,0 & 3,0 & 14,0 \\
& PNS & 42 & 42,0 & 42,0 & 56,0 \\
POLRI & 8 & 8,0 & 8,0 & 64,0 \\
SWASTA & 10 & 10,0 & 10,0 & 74,0 \\
WIRASWASTA & 5 & 5,0 & 5,0 & 79,0 \\
WIRAUSAHA & 21 & 21,0 & 21,0 & 100,0 \\
Total & 100 & 100,0 & 100,0 & \\
\hline
\end{tabular}

Secara deskripsi statistik dari jumlah jawaban variabel kebiasaan mengikuti pelajaram (X1), kebiasaan membaca buku teks (X2), kunjungan ke perpustakaan (X3), kebiasaan menghadapi ujian (X4), kebiasaan mencari data (X5) yaitu :

\section{Tabel 4.5 Descriptive Statistics}

\begin{tabular}{|l|l|l|l|l|l|l|}
\hline & N & Minimum & Maximum & Mean & $\begin{array}{l}\text { Std. } \\
\text { Deviation }\end{array}$ & Variance \\
\hline kebiasaanmengikutipelajaran & 100 & 2 & 5 & 3,51 &, 577 &, 233 \\
Kebiasaanmembacabuku & 100 & 2 & 5 & 3,64 &, 646 &, 356 \\
Kebiasaankunjunganperpustakaan & 100 & 1 & 5 & 2,85 &, 769 &, 455 \\
Kebiasaanmenghadapiujian & 100 & 2 & 5 & 3,79 &, 686 &, 371 \\
Kebiasaanmencaridata & 100 & 2 & 5 & 3,90 &, 710 &, 427 \\
Valid N (listwise) & 100 & & & & & \\
\hline
\end{tabular}

Dari tabel diatas dapat dilihat bahwa variabel mengenai kebiasaan mengikuti pelajaran, membaca, kebiasaan membaca buku, kebiasaan kunjungan ke perpustakaan, kebiasaan menghadapi ujian dan kebiasaan mencari data mempunyai rata rata diatas 2,5, sehingga dapat dikatakan rata rata jawaban seluruh responden terhadap variabel tersebut diatas tidak terlalu sering dan jika dilihat dari tingkat penyebarannya adalah homogeny, hal ini ditunjukkan dengan koefisien variasi yang kecil dari 0,5 . 


\section{B. Uji Reliabilitas}

Tabel. 4.6 Reliability Statistic

\begin{tabular}{|l|l|}
\hline Cronbach's Alpha & N of Items \\
\hline, 821 & 5 \\
\hline
\end{tabular}

Hasil perhitungan dengan menggunakan SPSS17.00 diatas menunjukkan bahwa jumlah variabel sebanyak 5 dan didapatkan Cronbach's alpha $(\alpha)$ sebesar 0,821 dengan demikian variabel diatas adalah sangat reliabel.

\section{Uji Normalitas}

Hasil Uji Kolmogorov-Smirnov tampak di bawah ini :

Tabel 4.7 Hasil One-Sample Kolmogorov-Smirnov Test

\begin{tabular}{|ll|l|}
\hline & & $\begin{array}{l}\text { Unstandardized } \\
\text { Residual }\end{array}$ \\
\hline $\mathrm{N}$ & Mean & 100 \\
Normal Parameters & a,b & Std \\
& Absolute &, 122 \\
& Positive &, 122 \\
Most Extreme Differences & Negative &,- 067 \\
& & 1,222 \\
Kolmogorov-Smirnov Z & &, 301 \\
Asymp. Sig. (2-tailed) & & \\
\hline
\end{tabular}

a. Test distribution is Normal.

b. Calculated from data.

Berdasarkan hasil Uji diatas dapat diketahui bahwa nilai signifikansi sebesar 0,301 lebih besar dari 0,05. Sehingga dapat disimpulkan bahwa data yang diuji berdistribusi normal

\section{Uji Autokorelasi}

Dari penelitian ini telah dilakukan uji autokorelasi dengan hasil sebagai berikut :

Tabel. 4.8 Model Summary ${ }^{b}$

\begin{tabular}{|c|c|c|c|c|c|}
\hline Model & $\mathrm{R}$ & $\begin{array}{l}\mathrm{R} \\
\text { Square }\end{array}$ & $\begin{array}{l}\text { Adjusted R } \\
\text { Square }\end{array}$ & $\begin{array}{l}\text { Std. Error } \\
\text { of the } \\
\text { Estimate }\end{array}$ & $\begin{array}{l}\text { Durbin- } \\
\text { Watson }\end{array}$ \\
\hline 1 &, $544^{\mathrm{a}}$ &, 281 &, 278 &, 80100 & 1,963 \\
\hline
\end{tabular}

a. Predictors: (Constant), x5, x3, x1, x2, x4 
b. Dependent Variable: y

Dari hasil output di atas didapat nilai DW yang dihasilkan dari model regresi adalah 1,620. Sedangkan dari tabel DW dengan signifikansi 0,05 dan jumlah data $(\mathrm{n})=$ 100 , seta $\mathrm{k}=5$ ( $\mathrm{k}$ adalah jumlah variabel independen) diperoleh nilai dL sebesar 1,57 dan dU sebesar 1,78 (lihat lampiran). Karena nilai DW (1,963) berada pada daerah antara dU dan 4-dU, maka tidak menghasilkan kesimpulan tidak ada autokorelasi antar variabel.

\section{E. Uji Hipotesis}

Dari hasil uji regresi sederhana ini dapat dijelaskan sebagai berikut :

Tabel 4.9 ANOVA $^{\mathrm{a}}$

\begin{tabular}{|ll|l|l|l|l|l|}
\hline Model & & Sum of Squares & df & Mean Square & F & Sig. \\
\hline \multirow{2}{*}{1} & Regression & 11,347 & 5 & 4,069 & 2,668 &, $000^{\mathrm{b}}$ \\
& Residual & 89,912 & 94 &, 435 & & \\
& Total & 101,259 & 99 & & & \\
\hline
\end{tabular}

a. Dependent Variable: PRESTASI

Tabel 4.10 Model Summary ${ }^{b}$

\begin{tabular}{|l|l|l|l|l|l|}
\hline $\begin{array}{l}\text { Mod } \\
\mathrm{el}\end{array}$ & $\mathrm{R}$ & $\mathrm{R}$ Square & $\begin{array}{l}\text { Adjusted } \\
\text { Square }\end{array}$ & $\begin{array}{l}\text { Std. Error of the } \\
\text { Estimate }\end{array}$ \\
\hline 1 &, $544^{\mathrm{a}}$ &, 281 &, 286 & \multicolumn{2}{|c|}{, 801} \\
\hline
\end{tabular}

a. Predictors: (Constant), X5, X3, X1, X2, X4

b. Dependent Variable: PRESTASI

b. Predictors: (Constant), X5, X3, X1, X2, X4

Dari hasil uji ANOVA (analisis of variance) untuk menguji ada tidaknya hubungan pengaruh kelima variabel independent terhadap variabel dependent (multi regresion), dapat diperhatikan bahwa F pada tabel diatas adalah 2,668. Sedangkan F tabel ( $\alpha$ $0,05)$, (numerator $=4$ dan denumerator $=95$ ) adalah 2,525.

Jadi $\mathrm{F}$ hitung $>\mathrm{F}$ tabel $(\alpha 0,05)$

Dengan demikian Ho ditolak dan Ha diterima, dapat ditarik kesimpulan bahwa kelima variabel kebiasaan mengikuti pelajaran, kebiasaan membaca buku teks, kebiasaan 
kunjungan ke perpustakaan, kebiasaan menghadapi ujian dan kebiasaan mencari data berpengaruh terhadap indeks prestasi.

Pengaruh korelasi indeks prestasi terhadap kebiasaan mengikuti pelajaran, kebiasaan membaca buku teks, kebiasaan kunjungan ke perpustakaan,

kebiasaan menghadapi ujian dan kebiasaan mencari data.

Pada bagian ini menunjukkan pasangan korelasi kelima variabel kebiasaan mengikuti pelajaran, kebiasaan membaca buku teks, kunjungan ke perpustakaan, kebiasaan menghadapi ujian dan kebiasaan mencari data terhadap indeks prestasi adalah sebesar 0,544. Sedangkan $\mathrm{R}^{2}$ (indek determinasi) adalah 0,281 , hal ini menunjukkan bahwa sumbangan dari pegaruh secara bersama sama (muti regresion) antara kebiasaan mengikuti pelajaran, kebiasaan membaca buku teks, kebiasaan kunjungan ke perpustakaan, kebiasaan menghadapi ujian dan kebiasaan mencari data terhadap indeks prestasi adalah sebesar 54,4\%. Selebihnya 45,6\% dipengaruhi oleh faktor lain.

Tabel 4. 11 Coefficients ${ }^{\mathrm{a}}$

\begin{tabular}{|c|c|c|c|c|c|c|}
\hline \multirow{2}{*}{\multicolumn{2}{|c|}{ Model }} & \multicolumn{2}{|c|}{ Unstandardized Coefficients } & \multirow{2}{*}{$\begin{array}{l}\text { Standardized } \\
\text { Coefficients } \\
\text { Beta }\end{array}$} & \multirow[t]{2}{*}{$\mathrm{t}$} & \multirow[t]{2}{*}{ Sig. } \\
\hline & & B & Std. Error & & & \\
\hline \multirow{6}{*}{1} & (Constant) &, 256 &, 142 & & ,404 & ,431 \\
\hline & $\mathrm{X} 1$ &, 414 & 078 &, 176 & 3,442 &, 060 \\
\hline & $\mathrm{X} 2$ & ,386 & ,068 & 149 & 2,259 & ,026 \\
\hline & $\mathrm{X} 3$ &, 281 & 049 &, 118 & 2,026 &, 005 \\
\hline & $\mathrm{X} 4$ & ,279 &, 042 &, 158 & 2,011 & ,007 \\
\hline & X5 &, 137 & 031 & , 146 & 2,204 &, 023 \\
\hline
\end{tabular}

Keterangan :

$\mathrm{X} 1=$ Kebiasaan mengikuti pelajaran

$\mathrm{X} 2=$ Kebiasaan membaca buku teks

X3 = Kebiasaan kunjungan ke perpustakaan

$\mathrm{X} 4=$ Kebiasaan menghadapi ujian

$\mathrm{X} 5=$ Kebiasaan mencari data

Dari persamaan diatas dapat diartikan bahwa indkes prestasi akan bagus apabila kebiasaan mengikuti pelajaran, kebiasaan membaca buku teks, kebiasaan kunjungan ke perpustakaan, kebiasaaan menghadapi dan kebiasaan mencari data dibiasakan.

\section{KESIMPULAN DAN SARAN}




\section{A. Kesimpulan}

Beberapa hal yang dapat peneliti simpulkan dari penelitian ini adalah :

1. Terdapat pengaruh antara variabel kebiasaan mengikuti pelajaran terhadap indeks prestasi

2. Terdapat pengaruh antara variabel kebiasaan membaca buku teks terhadap indeks prestasi

3. Terdapat pengaruh antara variabel kebiasaan kunjungan ke perpustakaan terhadap indeks prestasi

4. Terdapat pengaruh antara variabel kebiasaan menghadapi ujian terhadap indeks prestasi

5. Terdapat pengaruh antara variabel kebiasaan mencari data terhadap indeks prestasi

6. Dari hasil regresi linera diperoleh persamaan : $Y=0,256+0,414 X_{1}+0,386 X_{2}+0,281 X_{3}+0,279 X_{4}+0,137 X_{5}$

7. Jika kebiasaan mengikuti pelajaran, kebiasaan membaca buku teks, kebiasaan berkunjung ke perpustakaan, kebiasaan mengahadapi ujian, dan kebiasaan mencari data dibiasakan maka indeks prestasi akan semakin meningkat.

\section{B. Implikasi}

Hasil penelitian memperlihatkan bahwa terdapat pengaruh kebiasan mengikuti pelajaran, kebiasaan membaca buku teks, kunjungan ke perpustakaan, kebiasaan menghadapi ujian dan kebiasaan mencari data dibiasakan terhadap indeks prestasi akademik tidak dapat dijadikan jaminan bahwa indeks prestasi akan tinggi pula. Untuk itu diharapkan pimpinan melengkapi koleksi buku perpustakaan tidak hanya dengan buku teks, juga data data sekunder seperti data BPS, publikasi ilmiah dan karya ilmiah lainnya dan para dosen agar senantiasa memberi latihan dan kuis sebagai latihan ujian.

\section{Saran}

Penelitian tentang perilaku belajar untuk penelitian berikutnya sebaiknya memperhatikan hal hal berikut :

1. Membandingkan perilaku belajar antara perikau belajar dengan waktu belajar di kampus 
2. Taruna pada umumnya, diharapkan memperhatikan perilaku belajarnya sendiri dan memiliki motivasi yang tinggi agar dapat mencapai prestasi yang diharapkan. Perilaku belajar di bangku sekolah yang selalu menerima apa yang diberkan oleh Doesn atau bersifat pasif sebaiknya ditinggalkan karena sistem pembelajaran di Sekolah Tinggi sudah menuntut kemandirian. Dosen hanya sebagai fasilitator saja, sedangkan mahasiswa dituntut untuk kreatif dan inovatif.

3. Dosen juga harus memperhatikan kondisi yang terjadi pada diri Taruna yang perlu dimotivasi agar Sekolah Tinggi tinggi dapat menghasilkan output yang berkualitas sesuai dengan tuntutan pangsa pasar.

4. Lembaga Sekolah Tinggi juga perlu meningkatkan fasilitas pembelajaran agar Taruna dapat melaksanakan segala aktivitas dengan baik.

\section{DAFTAR PUSTAKA}

Ahmadi, A., 1993, Cara Belajar Yang Mandiri Dan Sukses, Solo, CV. Aneka

Albrecht, WS., D.C. Clark, J.M. Smith, K.D Stock dan L.W. Woodfield, 1994, An Accounting Curiculum for The Next Century, Issues in Accounting Education, Fall, 401-425.

Fransisca, Maria, pengaruh perilaku belajar terhadap prestasi akademik mahasiswa akuntansi, 2010

Ghozali, Imam.2005. Aplikasi Analisis Multivariat. BPFE UNDIP. Semarang.

Laporan tahunan, Sekolah Tinggi Transportasi Darat, Tahun 2015

Nasution, S., 1987, Belajar Pendekatan Dalam Proses Belajar Mengajar, Jakarta : Bina Aksara.

Rosniza. 1995. Hubungan Kebiasaan Belajar Siswa dengan Prestasi Belajar pada Siswa Kelas IT SMA Negeri Beureuneuen, Skripsi S1, Banda Aceh: FKIP Universitas Syah Kuala (tidak dipublikasikan)

Slameto, 1991, Belajar dan factor factor yang mempengaruhinya, Jakarta : Rineka Cipta.

Slamento. 1991. Belajar dan Faktor-Faktor Yang Mempengaruhinya, Jakarta: Rineka Cipta

Sulfiana. 1995. Perbandingan Prestasi Belajar antara Siswa Putra dan Putri di Bidang Biologi pada Program II A2 di SMAN Kodya Aceh, Skripsi S1. Banda Aceh: FKIP Universitas Syah Kuala (tidak dipublikasikan) 